\title{
ESTIMATION OF ALONG WIND-INDUCED STRUCTURAL RESPONSE IN SAUDI ARABIA: CASE STUDIES ON TALL BUILDINGS
}

\author{
SAMAR D. DERNAYKA, GAYDAA AL ZOHBI \& FATIMAH AL WUHAYB
}

Department of Mathematical and Natural Sciences, Prince Mohammad Bin Fahd University,

Al Khobar, Kingdom of Saudi Arabia

\begin{abstract}
The scope of this study is to evaluate the performance of tall building and its effect on human comfort when subject to lateral wind load. Along-wind responses are determined for two case studies located in Saudi Arabia based on hourly wind data collection for the last 11 years (2009-2019). A detailed wind speed analysis was conducted by using Gumbel distribution method in order to calculate the basic wind speed for return periods ranging between 2 and 100 years. The results indicate that the largest lateral displacements are obtained for the highest reference wind speed. An extensive study of the building responses shows that enhancing the damping ratio can reduce the wind-induced pressures and mitigate the vibrations, and hence provide a higher degree of comfort for occupants. Increasing the return period seems to affect significantly the behavior of each building. The non-linear increasing profile of along wind-induced responses shows that each building has a certain cut-off return period that controls its classification under any of the considered Human sensitivity levels; depending on the value of damping ratio.

KEYWORDS: Along-Wind Acceleration, Wind-Induced Pressure, Structural Damping, Return Period \& Gumbel
\end{abstract}

Received: May 21, 2020; Accepted: Jun 11, 2020; Published: Aug 06, 2020; Paper Id.: IJAERDDEC20203

\section{INTRODUCTION}

Wind is found to be the dominant load when analysing tall buildings. It is constituted with a massive number of eddies of various sizes and features moving relatively along the Earth surface in a general stream. The interaction of these eddies with obstacles (i.e. buildings, Trees, etc.) largely contributes to their turbulence, and can consequently force the wind to quickly change speed as well as direction. The mean wind speed increases with height from the surface, due to surface friction. When the wind blows against a building, it causes a horizontal loading which results in a sway of the building. Occupants can then feel oscillations that may last for several minutes depending on the strength of the wind. At the design stage, Engineers have the role to ensure that the building's structure can withstand wind loads without any collapse. Furthermore, they need to verify that the performance of structures subject to wind loads will be adequate during their anticipated life from the standpoint of both structural safety and serviceability [1]. Once the construction is completed, Engineers can still monitor or predict the wind-induced building response based on continuous tracking of meteorological records and other structural variables. There will be always a potential to prevent any discomfort or unwanted vibration, either by enhancing the design parameters or by installing devices, within the building, which can reduce the amplitude of the vibration (i.e. Tuned mass damper). 
As the building height increases, the wind impact becomes more significant. Moreover, structures with a height above $150 \mathrm{~m}$, known as high-rise, are more vulnerable to wind pressures. Vibration of tall buildings due to wind can be characterized by along-wind, across-wind and torsional vibration. The primary source of along-wind motion is the pressure fluctuations in windward and leeward wall; which are affected by the nature of the turbulent wind and the interaction with the structure itself. The wind flow gives rise to the gustiness of strong winds in the lower levels of the atmosphere. The average wind speed over a short time of period (ten minutes) tends to increase with height. Cross-wind oscillations are associated with other phenomena-giving rise to dynamic response of structures in wind. These include buffeting, vortex shedding, galloping and flutter. Torsional vibration is usually due to aerodynamic coupling in various degrees of freedom. Thus, the response in the along-wind direction depends mainly on (1)turbulence intensity; (2) size reduction effects; and (3) dynamic amplification (resonance) [2].The gust factor is considered to be the fundamental parameter in predicting along-wind building responses. Slender structures can be sensitive to dynamic response in line with the wind direction as a consequence of turbulence buffeting.

The wind-induced response in tall buildings also depends on, among other factors, wind speed characteristics (basic wind speed, direction and return period), building aspect ratio (ratio of its height over the shortest side of its plan), surface roughness, structural damping ratio, and the structural property that may magnify the wind loads (resonance).In addition, structures that are built with high-strength lightweight materials, longer floor spans and more flexible framing systems are more prone to vibrations.

Wind events can cause severe and / or sustained vibratory motion in high-rise buildings, which can be detrimental to both the structure and occupants. Therefore, an important problem associated with wind-induced motion of buildings is concerned with human response to vibration and perception of motion. The literature shows that serviceability considerations govern the design and not strength issues [3, 4]; more particularly for buildings with slenderness (aspect ratio) greater than five. The serviceability under wind loads is measured by the amount of lateral displacements and acceleration [5]. Although many studies have tended to evaluate the human response to building vibration, there is no generally accepted international standard for comfort criteria in tall buildings [6]. Differences between the commonly accepted criteria arise from diversity of regions and cultures. Moreover, the human perception to building vibration might be subjective; some humans are very sensitive to vibration to the extent that they are not able to tolerate even relatively low levels of stress and strain. This may vary from a slight feeling of discomfort to a complete intolerance.

In light of the above, the interest is in using the adequate values and limitations of all the factors that may significantly affect the evaluation of wind-induced structural response of a building under any potential lateral load. Practical engineering codes have settled clear guidelines about the majority of involved parameters. However, there is still some uncertainty surrounding the damping ratio. Constant damping ratios, as recommended in current codes or standards for dynamic analysis of tall buildings, may lead to significant underestimation of the response level [7]. The value of the damping ratio varies from one structural code to the other due to the difference in countries and regions[6] but the most used values range between $0.01(1 \%)$ and $0.05(5 \%)$. Many studies have investigated the effect of the damping ratio on the building responses. Most of the obtained results agreed that by enhancing the inherently low structural damping, the wind induced loads and responses could be reduced $[2,5,7,8]$. Other parameters were also explored like the basic wind speed, return period and slenderness. 
The building examined in [8] refers to a 150m tall reinforced concrete rectangular prism model (36 m x $20 \mathrm{~m})$ with slenderness equal to 8 , and natural frequency of $0.147 \mathrm{~Hz}$. The building model assumed to be located in urban category Terrain was examined in the x-direction, by using ASCE7-10 methods. The results indicated that the basic wind speed and damping ratio have present a significant impact on the building induced motion. The minimum values of alongwind acceleration are obtained for the maximum structural damping (0.07), and these values are increased by 2.65 times when damping gets reduced to 0.01 . The peak acceleration calculated for a high basic wind speed of $170 \mathrm{~km} / \mathrm{h}$ reached 0.5 $\mathrm{m} / \mathrm{s}^{2}$, and it decreased to $0.05 \mathrm{~m} / \mathrm{s}^{2}$ when the basic wind speed decreased to $80.46 \mathrm{~km} / \mathrm{h}$.

The research conducted in [5]focused on the prediction of along-wind induced response of a $225 \mathrm{~m}$ tall building $(\mathrm{f}=0.14 \mathrm{~Hz})$ with a cross section of $64 \times 23 \mathrm{~m}^{2}$; under a range of damping ratios from $0.8 \%$ to $4 \%$, which are mainly considered for reinforced concrete structures. The constructed building with slenderness equal to 10, is located in North Italy, and optimized for office use. The corresponding analysis showed that the basic wind speed decreases as the return period gets smaller. The obtained basic wind speeds were respectively $35 \mathrm{~m} / \mathrm{s}$ for 100 years, $32 \mathrm{~m} / \mathrm{s}$ for 50 years and $27 \mathrm{~m} / \mathrm{s}$ for 10 years return period. For 10 years return period, the estimated acceleration at the top of the building for $1 \%$ damping was $0.45 \mathrm{~m} / \mathrm{s}^{2}$, it decreased to $0.25 \mathrm{~m} / \mathrm{s}^{2}$ when the damping ratio increased up to $4 \%$. Thus, it was concluded that the damping shall be increased beyond $4 \%$ in order to get to the desired value (below $0.2 \mathrm{~m} / \mathrm{s}^{2}$ ).

The building discussed in [7] is $367 \mathrm{~m}$ tall building located in Hong Kong ( $0.253 \mathrm{~Hz}$ in the X-direction) under real wind fluctuations recorded during the passage of Typhoon Sally. The damping ratio was varied in the range of $0.5 \%-2 \%$. It was found that the peak displacement and acceleration calculated at the top of the building are inversely proportional to the variation of damping ratio. The highest values of peak displacement $(6.34 \mathrm{~mm})$ and peak acceleration $\left(3.86 \mathrm{~cm} / \mathrm{s}^{2}\right) \mathrm{were}$ found for the highest damping ratio of $0.55 \%$. When the damping ratio increases, the peak displacement and acceleration decrease until reaching $4.71 \mathrm{~mm}$ and $2.56 \mathrm{~cm} / \mathrm{s}^{2}$ respectively at the highest used damping value of $2 \%$. It was also found that the amplitude of displacement in cross- wind is about 1/3-1/2 less than that in along-wind direction.

Table 1: Human Sensitivity Levels Against Acceleration[3]

\begin{tabular}{|c|c|l|}
\hline Level & Acceleration $\left(\mathbf{m} / \mathbf{s}^{2}\right)$ & \multicolumn{1}{|c|}{ Effect } \\
\hline 1 & $<0.05$ & Humans cannot perceive motion. \\
\hline 2 & $0.05-0.1$ & Sensitive people can perceive motion. Hanging object may move slightly. \\
\hline 3 & $0.1-0.25$ & Level of motion may affect deskwork. Long term exposure may produce motion sickness \\
\hline 4 & $0.25-0.4$ & Deskwork becomes difficult or almost impossible. \\
\hline 5 & $0.4-0.5$ & Difficult to walk naturally and standing people may lose balance. \\
\hline 6 & $0.5-0.6$ & Unable to walk naturally. \\
\hline 7 & $0.6-0.7$ & People cannot tolerate motion or walk. \\
\hline 8 & $>0.85$ & Objects begin to fall. \\
\hline
\end{tabular}

This paper aims to evaluate the along wind induced pressure, displacement and accelerations of two tall buildings located in the Kingdom of Saudi Arabia, under real extreme wind speed data; in absence of any recent measurements of the building's wind -induced motion response. Calculations were carried out, in compliance with the guidelines of the SBC [9] and ASCE7-10 method, by looking at the effect of three parameters (1) the damping ratio that is varied in the range of 0.01 to 0.07 ; (2) the basic wind speed and (3) the return period. The initial Basic wind speed ( 3 sec gust speed at $10 \mathrm{~m}$ above the ground) was obtained from the continuous tracking of hourly wind speed data over the past 11 years (2009 to 2019). The evaluation of building's acceleration and its effect on the occupant, were judged based on the human perception levels and acceleration values shown in table 1 . 


\section{BUILDING CONFIGURATION}

The case studies examined in the present study are two tall buildings having regular rectangular shape and located in two different cities of Saudi Arabia. The considered structures are Dhahran Tower and Golden Tower (figure 1).

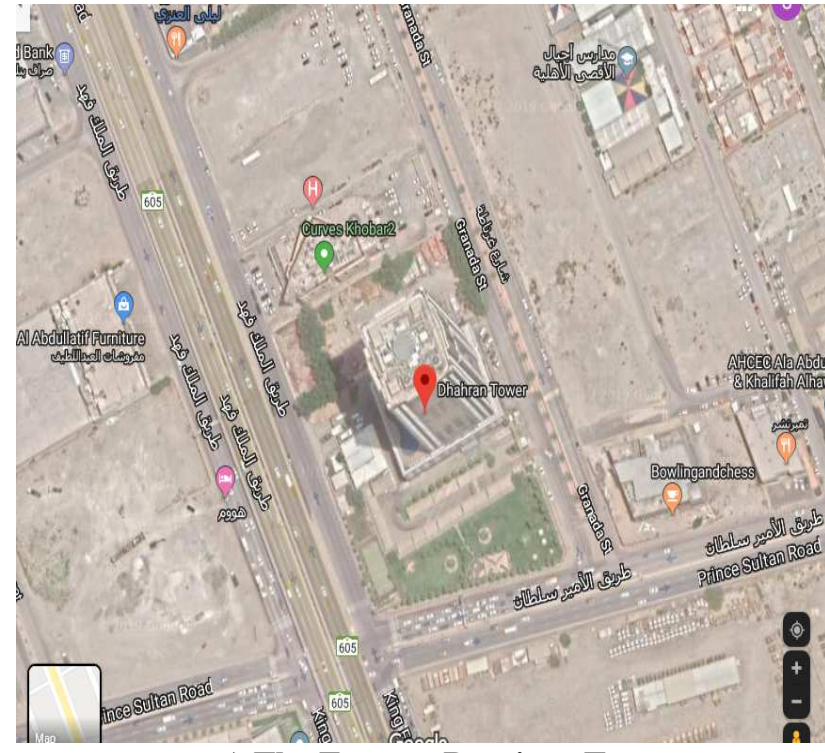

a) The Eastern Province Tower.

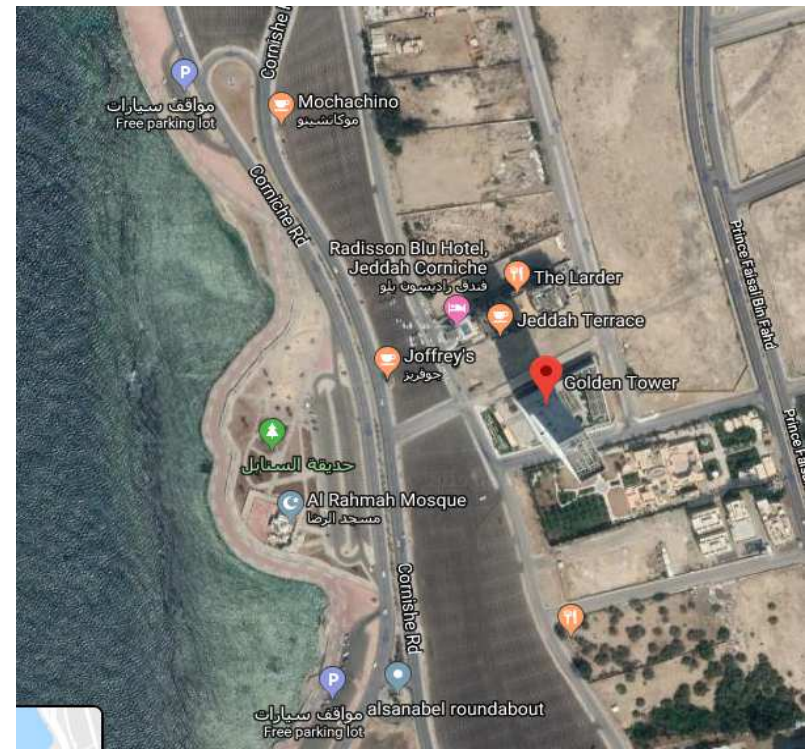

b) Jeddah Cornice.

Figure 1: View from Satellite for Case Studies of Tall Buildings.

Dhahran Residential tower, also known as Al Suwaiket tower, is situated in the Eastern Province of the Kingdom of Saudi Arabia. It is the unique Residential Skyscraper in the heart of Al Khobar. The construction project started in 2007 and was completed in 2012. This 200m height tower is a multi-use building that houses over 200 apartments with multiple recreational facilities, in addition to some offices, a nursery and preschool distributed over 46 floors. It is made of concrete, with aluminum cladding and double glazing.

Golden Tower is mainly a residential building sitting on a prominent position on Jeddah Corniche; on the northern stretch. Its construction ended in 2018 and it is ranked as the second tallest tower in Jeddah with a height of $205 \mathrm{~m}$. It combines luxury, modernity and old concepts of building facades in this area of Saudi. This tower offers a panoramic view due to a glass facade ranging from 18 to $40 \mathrm{~m}$, and large bi-folding windows at the balcony balustrades to allow the residents to close the windows and enlarge their living spaces while still taking advantage of the Red Sea views. In terms of residency, it has a wide variety of units, health clubs and swimming pools distributed over 48 stories above the ground. figure 2 provides a zoom in to facades of both: Dhahran and Golden towers.

These two buildings were selected due to their compliance with the criteria of height, shape and location. Both are higher than $150 \mathrm{~m}$, which meets the tall buildings whose height usually falls in the range of 150 to $300 \mathrm{~m}$. They do not present significant irregularities or curving along their floor plan or height, so they can be considered under the category of regular rectangular buildings. In case of Dhahran Tower, the three larger lower floors will be treated as similar to the floors above to simplify the calculations. 


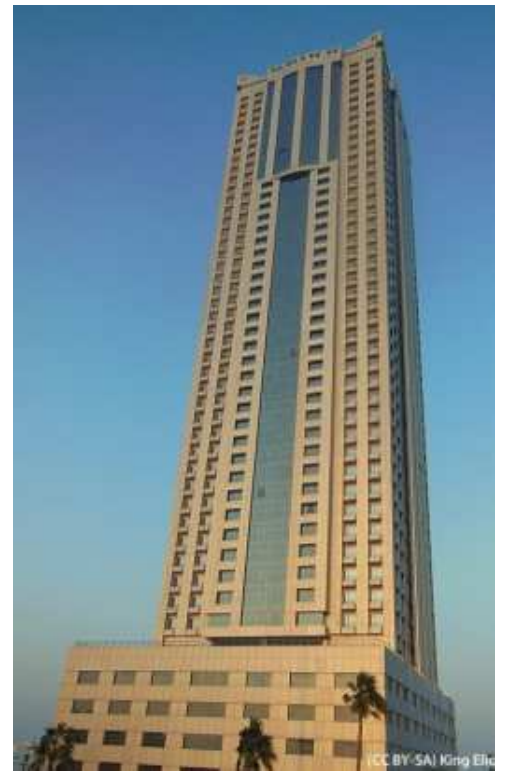

a) Dhahran Tower

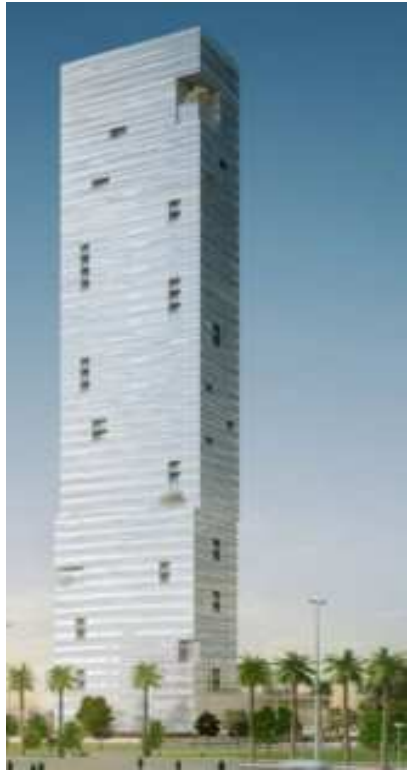

b) Golden Tower

Figure 2: Buildings Facades.

Tall buildings normally experience various modes of vibrations in the $\mathrm{x}$-direction, the $\mathrm{y}$-direction as well as torsion caused by turbulent wind fluctuations. In the current paper, the wind-induced building response of the two buildings is evaluated in the $\mathrm{x}$-direction as shown in figure 3 . This vibration refers to the fundamental mode shape. The dimension $\mathrm{D}$ refers to the side that is parallel to wind direction; while $\mathrm{B}$ is normal to the wind flow.
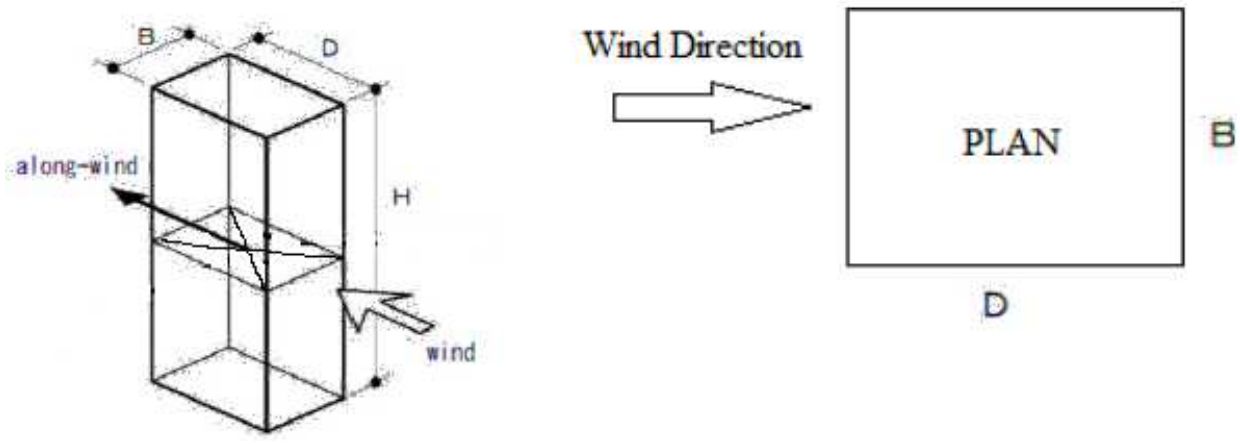

Figure 3: Analysed Wind Direction.

The natural frequency of the structure is the number of complete cycles of vibration per second, and equals the inverse of the time period $\mathrm{T}$ taken by the structure to complete one full cycle of vibration. Thus, the natural frequencyn_0can be calculated by the following formula:

n_0 $=1 / \mathrm{T}$

The authors in [10] suggested that the fundamental frequency of concrete tall building is inversely proportional to the building height ( $\mathrm{n} \_0 \sim 1 / \mathrm{H}$ ). $\mathrm{T}$ is related to the number of stories $\mathrm{N}$ in the structure and it is estimated by the following relation

$$
T=0.1 N
$$

The calculated natural frequency along with other characteristics of the two studied towers are summarized in table 2 
Table 2: Building Characteristics Selected for the Case Study

\begin{tabular}{|c|c|c|c|c|c|c|c|}
\hline Building & Location & Exposure & StoriesD & $(\mathbf{m})$ & B (m) & Height (m) & $\begin{array}{c}\text { Natural } \\
\text { Frequency }\end{array}$ \\
\hline Dhahran Tower & Dhahran & Sub-urban & 46 & 38.68 & 29.58 & 200 & 0.2017 \\
\hline Golden Tower & Jeddah & Sub-urban & 48 & 39 & 26 & 205 & 0.2 \\
\hline
\end{tabular}

The actual dimensions reveal high slenderness for both towers. Dhahran tower has a slenderness $\lambda$ equal to 7.8 ; while Golden Tower has $\lambda$ of 6.7; which infers that some comfort problems would occur under high wind peaks. In fact, slenderness close to 8 refers to a border between a very tall building and a stubby chimney as per [5].

\section{WIND SPEED DATA}

The available data include hourly wind speeds recorded at $10 \mathrm{~m}$ above the ground from 2009 to 2019, for Dhahran and Jeddah cities. They are collected from the meteorological weather website, Time and Date [11]. The annual extreme values of daily average wind speed are then generated; which is desirable for the annual extreme value analysis over a period of 11 years. The variation of the annual extreme wind speeds is plotted in time series as shown in figure 4.

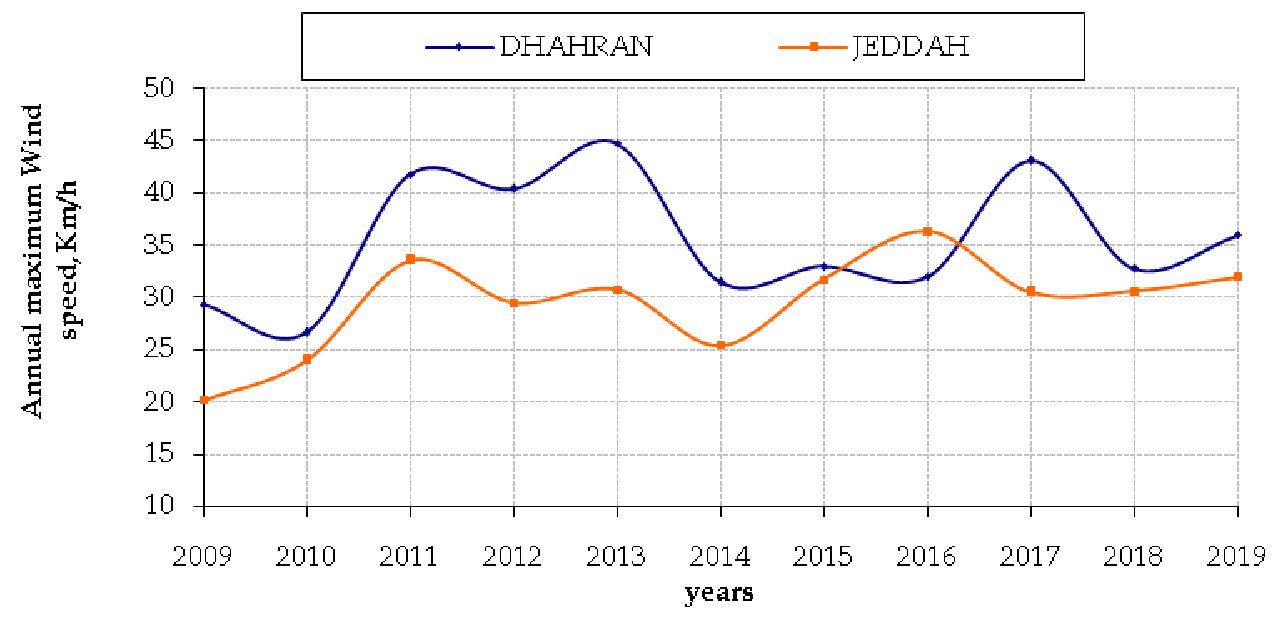

Figure 4: Annual Maximum Wind Speed in Dhahran and Jeddah.

It can be noticed that the extreme annual wind speed values in Jeddah were sometimes following the fluctuations seen in Dhahran, through the past eleven years; with higher extremes in Dhahran that reached $45 \mathrm{~km} / \mathrm{h}$ in 2013 . The annual extreme wind speed increases gradually starting from 2009 until 2011, and then it continues to fluctuate between increasing and decreasing values until reaching its peak of $36 \mathrm{~km} / \mathrm{h}$ in 2016 . Dhahran was prone to greater extreme wind speed values. The corresponding graph shows a bell shape between 2016 and 2018 where again the peak is hit in 2017.

\section{METHODOLOGY}

Wind data analysis is substantial to acquire enough information on the extreme winds that might affect the building structural response during its lifetime as well as the occupant comfort. The evaluation of extreme wind values requires the annual extremes to be modeled in accordance with the generalized extreme value theory or distribution. In probability theory and statistics, the generalized extreme value distribution is a family of various probability distributions developed to estimate models that predict events occurring at extremely low probabilities (i.e. floods, winds,etc.). The analysis of wind data is conducted herein by using the distribution type I, also known as Gumbel distribution, which is a particular technique of the extreme values distribution. 


\subsection{Gumbel Probability Distribution Function}

Gumbel distribution is considered to be the most appropriate probabilistic model for extreme wind behavior. It follows the assumption that the extreme values from different years are seriously independent. Hence, each record in the serious of the largest annual wind speeds will contribute to the probabilistic behavior of the extreme winds. Moreover, the wind speed distribution will be more accurate and efficient if the number of values is higher. Thus, a long-term record of wind speed data for more than eight years is preferable to obtain better prediction of wind parameters [12].

The Type I (Gumbel) extreme value probability distribution function, $F_{I}(v)$ that provides the probability of not exceeding the wind speed is defined as [12].

$$
F_{I}(v)=\exp \left[-\exp \left(-\frac{v-\alpha}{\beta}\right)\right]
$$

where $\alpha$ and $\beta$ are the location and scale parameters, respectively.They are estimated from the observed data.

Gumbel distribution belongs to the location-scale family of probability distributions. It is characterized by two parameters: the location parameter and scale parameter. In wind data analysis, the location parameter (mode) that usually indicates the direction of shift of the data, refers to the wind speed seen more frequently among the extreme wind values. While the scale parameter is a dimensionless scalar that describes the distribution of the data. The larger the scale parameter, the more spread out the distribution.

The distribution parameters of Eq. (3) can be generally estimated by using two methods: the method of order statistics (MOS) and the method of moments (MOM) [12].The method of order statistics (MOS) is known by its reliability to provide reasonable analysis for long- term wind Data (equal or exceeding 9 years) as per [12-14], and. Furthermore, it implies a minimum number of errors when calculating the basic wind speed afterwards [13]. The method of order (MOS) performs a simple least regression graphically using the Gumbel reduce variant as the independent variable and the ranked wind speed as the dependent variable. A description of the (MOS) method is presented herein. The detailed procedure shows how to obtain the cumulative distribution function, $F_{i}$ the probability of exceedance, $E_{i}$ the return period $\mathrm{T}$, the location parameter $\alpha$ (mode) and the scaling parameter. $\beta$

The annual extreme wind speed values are collected over a certain time period; and arranged in an increasing order of magnitude by assigning rank of $1,2,3 \ldots \mathrm{N}$.

The empirical cumulative probability for each data point for rank (i) is assigned by using the following relation given by Weibull Formula [15].

$$
F_{i}=\frac{i}{N+1}
$$

where $F_{i}$ is the non-exceedance probability, (i) is the rank in ascending order and $\mathrm{N}$ is the number of annual maximum wind speeds. $F_{i}$ is transformed into Gumbel reduce variate, which can be defined by: 


$$
y_{i}=-\ln \left(-\ln \left(F_{i}\right)\right)
$$

The graph of the maximum annual wind speed versus the Gumbel reduce variate will then produce the following equation:

$$
x_{i}=\alpha+\beta\left(-\ln \left(-\ln F_{i}\right)\right)
$$

or

$$
x_{i}=\alpha+\beta y_{i}
$$

The parameters $\alpha$ and are $\beta$ represented respectively by the intercept and the mode obtained from the linear Gumbel fitting graph. The theoretical return period is the average time within which a given wind speed will be exceeded just once. The probability that a certain speed will be exceeded is [15].

$$
E_{i}=1-F_{i}
$$

The return period is the reciprocal of the probability of exceedance E_i [15]

$$
T=\frac{1}{1-F_{i}}
$$

Thus, the non-exceedance $F_{i}$ probability can be written in terms of the return period as

$$
F_{i}=1-\left(\frac{1}{T}\right)
$$

By determining all the parameters of Gumbel distribution, the extreme wind of specified return period will be found by the combining Equations (5) and (8) as [15]

$$
x_{E}=\alpha+\beta(-\ln (-\ln (1-1 / T))
$$

\subsection{Basic Wind Speed}

The basic wind speed is defined as the wind speed measured at the height of 10 meters above ground over a chosen recurrence interval. This speed is usually established by extreme value analysis of the maximum annual wind data collected over a geographical region. The basic wind speed, also called 3-seconds (sec) average wind speed is found by extrapolating Eq. (10) to any selected return period and by applying the distribution parameters determined from the graphical Gumbel distribution. As previously mentioned, the return period designates the estimated averaged time between wind events to occur.

\subsection{Extreme Wind Speed at the Top of the Building}

The wind velocity at building height can be calculated directly from the power law profile; that relates the mean wind speed at any height with the basic wind speed measured at $10 \mathrm{~m}$ as follow [14] 


$$
\left(\frac{V_{H}}{V_{10}}\right)=\left(\frac{Z_{H}}{Z_{10}}\right)^{\alpha}
$$

where $\alpha$ is the 3 -sec gust speed power law exponent based on the terrain roughness.

\section{ESTIMATION OF ALONG-WIND BUILDING RESPONSES}

The Calculations carried within this paper are based on the recommendations of Saudi Building Code [9]and American code[16], for the design and construction of Main Wind Force -resisting system as per the analytical method. For the 2 case studies (Dhahran Tower and Golden Tower), the following hypotheses are adopted:

- $\quad$ Surface Roughness B: Urban and suburban areas.

- Exposure Category B: shall apply where the ground surface roughness condition, as defined by Surface Roughness B, prevails in the upwind direction for a distance of at least $800 \mathrm{~m}$ or 10 times the height of the building, whichever is greater.

- Geometry: Regular shaped with no unusual geometrical irregularity in spatial form.

- Openings: The buildings are partially enclosed if the total area of openings in a wall that receives positive external pressure exceeds the sum of the areas of openings in the balance of the building envelope (walls and roof) by more than $10 \%$.

- Structure: flexible since the fundamental natural frequency is less than $1 \mathrm{~Hz}$.

- Importance factor I $=1.15$, Category III (including the buildings that represent substantial hazard to human life in case of failure).

- The buildings are not subject to topographic effects.

- $\quad$ The basic wind speed $V(\mathrm{~km} / \mathrm{h})$ is obtained from Climatic Data as per Section 3.2.

\subsection{Along Wind-Induced Pressure}

The external design pressure on the building is estimated using the following equation [9]:

$$
p=q G_{f} C_{P}-q_{i}\left(G C_{p i}\right)
$$

where $p$ is the peak pressure acting statically on the building surface, $q$ is the velocity pressure at the top of the building. Note that $q=q_{h}$ for windward walls, sidewalls and roofs evaluated at height h, $G_{f}$ is the gust effect factor, $C_{p}=0.7$ is the external pressure difference coefficient across the building width for side wall in partially enclosed buildings.

The product of internal pressure coefficient and gust effect factor $G C_{p i}$ depends on the building enclosure classification:

$G C_{p i}=0$ for open and $G C_{p i}= \pm 0.55$ for partially enclosed buildings. The plus and minus signs signify 
pressures acting towards and away from the surfaces respectively.

The velocity pressure $q\left(\mathrm{kN} / \mathrm{m}^{2}\right)$ is calculated based on the following formula [9]

$$
q_{h}=0,043 \cdot 10^{-3} k_{h} k_{z t} V_{h}^{2} I
$$

The parameter; $k_{h}=1.56$ refers to the velocity pressure exposure coefficient.

The Topographic factor $k_{z t}$ is taken as 1 in absence of wind speed-up effects usually due to isolated hills, ridges and escarpments. $V_{h}(\mathrm{~km} / \mathrm{h})$ is the velocity at the height of the building as found in Section 3.3

For Main Wind Force Resisting System (MWFRS) of flexible buildings and other structures, the Gust effect factor can be obtained by $[9,16]$ :

$$
G_{f}=0.925\left[\frac{\left(1+1.7 I_{\bar{Z}} \sqrt{g_{Q}^{2} Q^{2}+g_{R}^{2} R^{2}}\right)}{1+1.7 g_{V} I_{\bar{Z}}}\right]
$$

Where the peak factor for background response $g_{Q}$ and the peak factor for resonance response $g_{V}$ are taken as 3.4 .

The other parameters involved in the formula are explained as follow:

The Background response factor $\mathrm{Q}$ is calculated using the following relationship:

$$
Q=\sqrt{\frac{1}{1+0.63\left[\frac{B+h}{L_{\bar{Z}}}\right]^{0.63}}}
$$

$L_{\bar{Z}}$ is the length scale of turbulence; $L_{\bar{Z}}=l\left(\frac{\bar{Z}}{10}\right)^{\varepsilon}$ where $; \bar{Z}=0.6 h: l$ is the integral length scale factor equal to $100 \mathrm{~m}$.

The integral length scale is $\varepsilon=1 / 3$

The peak factor for resonance is calculated using the following relationship:

$$
g_{R}=\sqrt{2 \ln \left(3600 n_{1}\right)}+\frac{0.577}{\sqrt{2 \ln \left(3600 n_{1}\right)}}
$$

The Resonant factor $R$ is obtained by:

$$
R=\sqrt{\frac{1}{\beta} R_{n} R_{h} R_{B}\left(0.53+0.47 R_{l}\right)}
$$


with

$$
R_{n}=\frac{7.47 N_{1}}{\left(1+10.3 N_{1}\right)^{5}}
$$

and

$$
N_{1}=\frac{n_{1} L_{\bar{Z}}}{\bar{V}_{z}}
$$

The following expressions are given to calculate the remaining parameters:

$$
\begin{aligned}
& R_{l}=\frac{1}{\eta}-\frac{1}{2 \eta^{2}}\left(1-e^{-2 \eta}\right) \text { for } \eta>0 \\
& R_{l}=1 \text { for } \eta=0 \\
& R_{l}=R_{h} \rightarrow \eta=\frac{4.6 n_{1} h}{\bar{V}_{Z}} \\
& R_{l}=R_{B} \rightarrow \eta=\frac{4.6 n_{1} B}{\bar{V}_{Z}} \\
& R_{l}=R_{L} \rightarrow \eta=\frac{15.4 n_{1} L}{\bar{V}_{Z}}
\end{aligned}
$$

The mean hourly wind speed at height, $\bar{z}$ is theoretically determined by [9]:

$$
\bar{V} \bar{z}=\bar{b}\left[\frac{\bar{z}}{10}\right]^{\bar{\alpha}} V\left(\frac{1}{3.6}\right)
$$

with the constants given as $\bar{b}=0.45$ is the mean hourly wind speed factor; and $\bar{\alpha}=7$ represents the mean hourly wind speed power law exponent.

$\beta$ designates the structural damping ratio of the building. In general, the damping represents a dimensionless measure that describes how oscillations of a system decay after a certain excitation. For structures, knowing the damping ratio is essential in order to evaluate the building vibration, and how this does affect the occupant comfort. In the engineering, it is very difficult to estimate the structural damping, unless it is measured on the field. For this reason, some codes have set constant values to be used in the course of the design and prediction of building response.

\subsection{Along -wind Displacement and Acceleration $X_{\max }$}

ASCE7-10[16] provides clear provisions about the calculation of along-wind induced building response. The maximum along-wind displacement as a function of height above the ground surface is given 
$X_{\max (z)}=\frac{\phi_{(z)} \rho B h C_{f x} \hat{V}_{z}^{2}}{2 m_{1}\left(2 \pi n_{1}\right)^{2}} K G_{f}$

where, $\phi_{(z)}=\left(\frac{z}{h}\right)^{\xi}$ based on power law is a variation function that represents the mode shape of the building, $\xi$ is the along-wind mode shape exponent. The mode considered for calculations is the fundamental mode assumed to be linear. The used values of $\phi_{(z)}=0.8$ and $\xi=1.5$ arise from the mode shape corrections graphs for generalized wind loads, and especially lateral mode as per [17]. $\rho$ is the air density, $B$ is the horizontal dimension of building measured to normal direction, h is the height of the building. $C_{f x}$ refers to the mean along -wind force coefficient that is associated to the x-direction; and it depends on the ratio $\mathrm{h} / \mathrm{D}$ of structure. $\widehat{V}_{\bar{z}}^{2}$ is 3-second gust speed (basic wind speed) at height $\mathrm{z}, n_{1}$ refers to the natural frequency at mode $1, m_{1}$ is the modal mass calculated with $\int_{0}^{h} \mu(z) \phi^{2}(z) d z$ where is the mass per unit height. The mass distribution is assumed to be linearly distributed for tall structures, therefore $m_{1}=\rho_{B} W D h$ where $\rho_{B}$ represents the building density.

The parameter $\mathrm{K}$ is given by the following formula [16]

$$
K=\frac{1.65^{\bar{\alpha}}}{\bar{\alpha}+\xi+1}
$$

where $\bar{\alpha}$ is the exposure exponent of wind speed profile.

The rms along- wind acceleration $\sigma_{\bar{x}(z)}$ as a function of height above the surface is given by [16]

$$
\sigma_{\bar{x}(z)}=\frac{0.85 \phi_{z} \rho B h C_{f x} \bar{V}_{\bar{z}}^{2}}{m_{1}} I_{z} K R
$$

where $\bar{V}_{z}$ is the mean hourly wind speed at height z.

The maximum along-wind acceleration as a function of height above the ground surface is given by [16]

$$
\ddot{X}_{\max }(z)=g_{x} \sigma_{\bar{x}}(z)
$$

$g_{x}$ refers here to the peak factor for resonance mentioned Equation (15).

\section{RESULTS AND DISCUSSIONS}

\subsection{Analysis of Wind Data}

\subsubsection{Estimation of Distribution Parameters}

The mean extreme wind speed values, issued from continuous hourly wind data recorded over a period of 11 years (2009-2019), are obtained for both cities Dhahran and Jeddah; and arranged in an increasing order of magnitude by assigning rank of $1,2,3 \ldots \mathrm{N}$. The empirical cumulative probability is calculated as per Eq. (4). Extreme wind 
speedsare then plotted with respect to Gumbel Reduce Variate Eq. (5); by fitting a straight line to the data and resulting Gumbel extreme value distribution as shown in Figure 5, for both cities of Dhahran and Jeddah.

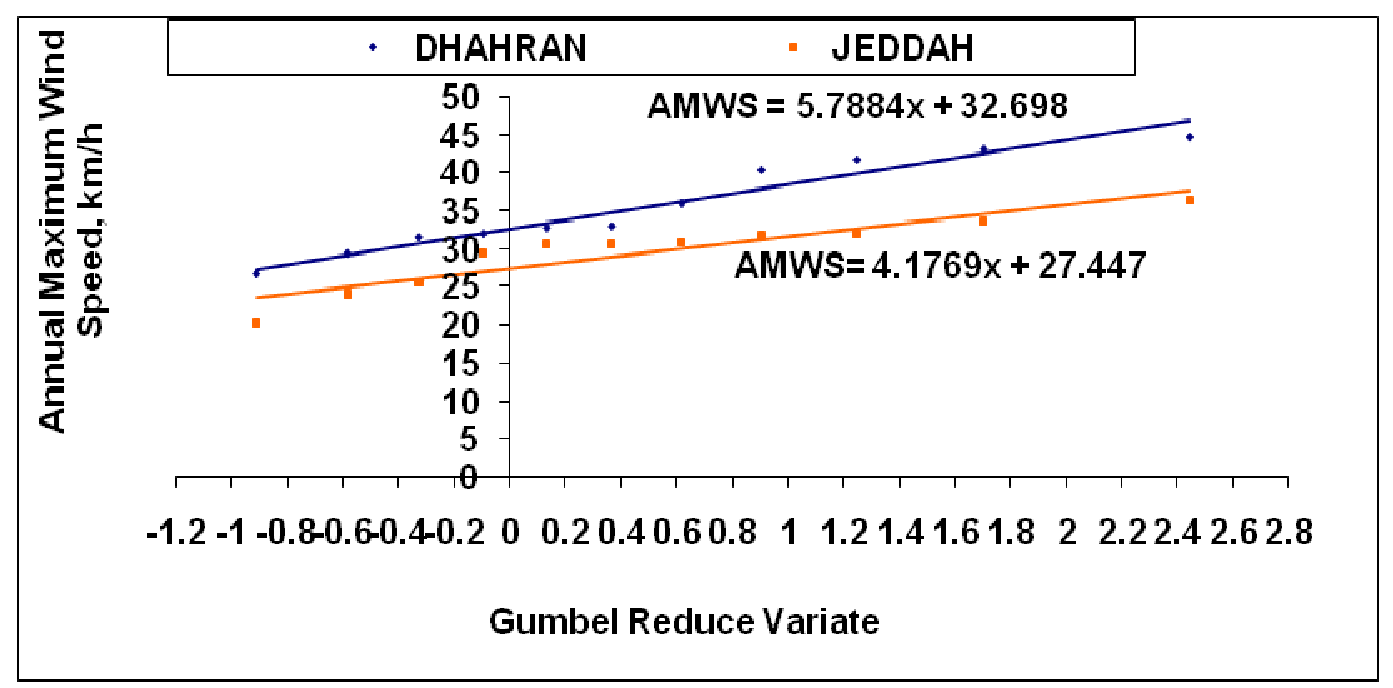

Figure 5: Gumbel Extreme Value Distribution for Wind Speed.

The graph shows the two equations for the Annual Maximum Wind Speed (AMWS) associated to both cities, as per Eq. (16). The slope of each regression line represents Gumbel scaling parameter (5.7884 for Dhahran and 4.1769 for Jeddah). The intercept refers to Gumbel location parameter $(32.698 \mathrm{~km} / \mathrm{h}$ for Dhahran and 27.447 $\mathrm{km} / \mathrm{h}$ in Jeddah), also called mode, which indicates the extreme wind speed value encountered often over the time period considered. It can be inferred from the graph that the annual extreme wind speed values are ranging in a larger interval, which means a wider distribution in Dhahran, since the scale parameter is higher. The two lines representing the wind speed distribution for Dhahran and Jeddah, present some convergence on the left side of the graph with a negative Gumbel reduce variate, also some wind speeds collide between 30 and $32 \mathrm{~km} / \mathrm{h}$ which is seen in the range of small probability $(-0.2-0.4)$. However, the divergence of the two lines becomes more pronounced after this range. It can be noticed that the high extreme wind speed values overcome $32 \mathrm{~km} / \mathrm{h}$, while those of Jeddah get lower. Overall, it can be said that the annual maximum wind speed of Dhahran overcomes that of Jeddah by $20 \%$ due to the difference in their modes.

\subsubsection{Estimation of Theoretical Return Periods}

Table 3 presents the ranked extreme annual wind speed as well as the theoretical return period $T$ as calculated from Eq.(7) for Dhahran and Jeddah. It can be noticed that extreme wind speeds having the same rank among the values collected in Dhahran and Jeddah, got the same return period, irrespective of their real value. Therefore, the return period depends on the length of the time record and the ranking of wind speed data as well. Also, the values of the return periods given in Table 3 reflect some fluctuations of the annual extreme wind speeds seen in Figure 1 especially in Jeddah. For instance, the recurrence interval calculated for the EWS of $31.75 \mathrm{~km} / \mathrm{h}$ is 3 years; which is true because almost the same EWS occurred in year $2018(30.63 \mathrm{~km} / \mathrm{h})$. However, this is not the case for Dhahran. The return period given for EWS=40.43 occurring in 2012 is 3 years, but the actual EWS occurring in 2016 was much lower (32 km/h). The extreme wind speed of Dhahran of $45 \mathrm{~km} / \mathrm{h}$ is recorded in 2013, while the extreme wind speed for Jeddah of $37 \mathrm{~km} / \mathrm{h}$ is recorded in 2016; and they both have the highest return period of 12 years. 
Table 3: Ranked Wind Speed and Return Periods for Annual Wind Extremes, 2009-2019

\begin{tabular}{|c|c|c|c|c|c|c|c|}
\hline \multicolumn{4}{|c|}{ DHAHRAN } & \multicolumn{4}{|c|}{ JEDDAH } \\
\hline Rank & Year & EWS (km/h) & Ti (Years) & Rank & Year & EWS (km/h) & Ti (Years) \\
\hline 1 & 2010 & 26.7 & 1.09 & 1 & 2009 & 20.20 & 1.09 \\
\hline 2 & 2009 & 29.4 & 1.20 & 2 & 2010 & 24.00 & 1.20 \\
\hline 3 & 2014 & 31.5 & 1.33 & 3 & 2014 & 25.47 & 1.33 \\
\hline 4 & 2016 & 32 & 1.50 & 4 & 2012 & 29.54 & 1.50 \\
\hline 5 & 2018 & 32.78 & 1.71 & 5 & 2017 & 30.54 & 1.71 \\
\hline 6 & 2015 & 33 & 2.00 & 6 & 2018 & 30.63 & 2.00 \\
\hline 7 & 2019 & 36 & 2.40 & 7 & 2013 & 30.79 & 2.40 \\
\hline 8 & 2012 & 40.43 & 3.00 & 8 & 2015 & 31.75 & 3.00 \\
\hline 9 & 2011 & 41.8 & 4.00 & 9 & 2019 & 32 & 4.00 \\
\hline 10 & 2017 & 43.13 & 6.00 & 10 & 2011 & 33.58 & 6.00 \\
\hline 11 & 2013 & 44.75 & 12.00 & 11 & 2016 & 36.37 & 12.00 \\
\hline
\end{tabular}

\subsubsection{Estimation of the Basic Wind Speed}

Table 4 provides the values of the Basic wind speed for the different considered return periods by using Eq. (10). Dhahran city presents the highest basic wind speed values $(35-63 \mathrm{~km} / \mathrm{h})$; in comparison with Jeddah whose basic wind speed is $20 \%$ lower $(29-50 \mathrm{~km} / \mathrm{h})$. Furthermore, it is noted that the basic wind speed increases when the return period is increased. However, when the return period exceeds 10 years, the rate of increase in the V10 is reduced, although the difference in recurrence interval gets bigger. For instance, the Basic wind speed registered in Dhahran is $35 \mathrm{~km} / \mathrm{h}$ for $\mathrm{T}=2 \mathrm{years}$ and 40 $\mathrm{km} / \mathrm{h}$ for $\mathrm{T}=4$ years; while the value reaches $55 \mathrm{~km} / \mathrm{h}$ for $\mathrm{T}=50$ years and $60 \mathrm{~km} / \mathrm{h}$ for $\mathrm{T}=100$ years. The same trend is noticed for Jeddah that has lower rate of change of Basic wind speeds when varying the return periods $(\mathrm{V} 10=29 \mathrm{~km} / \mathrm{h}$ for $\mathrm{T}=2$ years $\& 33 \mathrm{~km} / \mathrm{h}$ for $\mathrm{T}=4$ years; $\mathrm{V} 10=44 \mathrm{~km} / \mathrm{h}$ for $\mathrm{T}=50 \& 47 \mathrm{~km} / \mathrm{h}$ for $\mathrm{T}=100$ ).

Table 4: Basic Wind Speed Estimates for Different Return Periods using Gumbel Distribution

\begin{tabular}{|c|c|c|}
\hline \multirow{2}{*}{$\begin{array}{c}\text { Return Period } \\
(\text { Yr })\end{array}$} & \multicolumn{2}{|c|}{ Basic Wind Speed $(\mathbf{k m} / \mathbf{h})$} \\
\cline { 2 - 3 } & Dhahran & Jeddah \\
\hline 2 & 35 & 29 \\
\hline 4 & 40 & 33 \\
\hline 6 & 42 & 34 \\
\hline 10 & 46 & 37 \\
\hline 12 & 47 & 38 \\
\hline 50 & 55 & 44 \\
\hline 100 & 60 & 47 \\
\hline 200 & 63 & 50 \\
\hline
\end{tabular}

The variation of the basic wind speed with respect to the return period is also displayed graphically in figure 6 . It can be noticed that the two curves representing Dhahran and Jeddah do not present a linear behavior. The basic wind speed starts to increase gradually, and then the rate of increase gets smaller as the return period increases. It can be concluded that the basic wind speed almost stabilizes when exceeding the 100-year return period. 


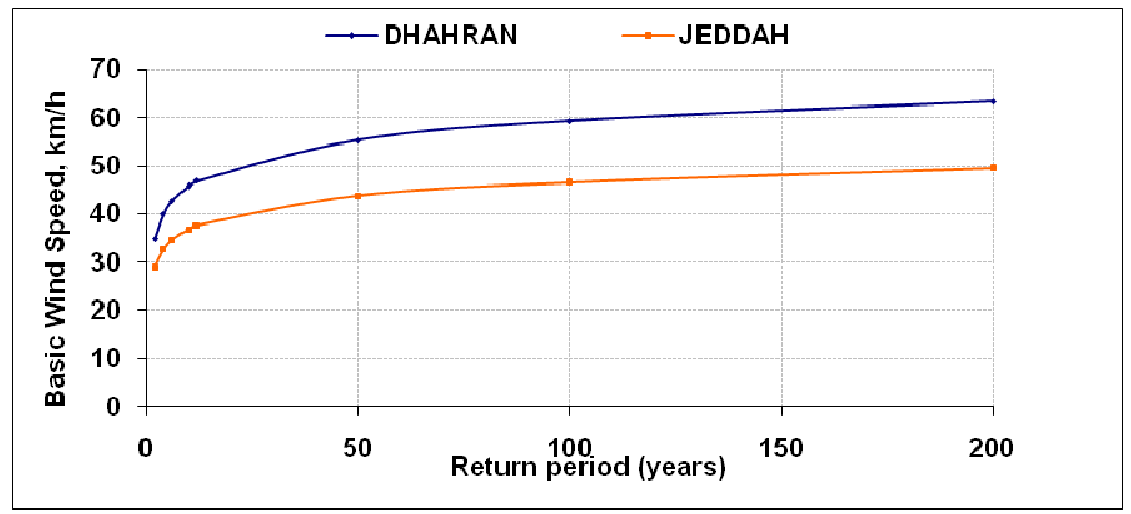

Figure 6: Variation of Basic Wind Speed with Respect to the Return Period.

\subsubsection{Estimation of the Extreme Wind Speed at the Top of the Building}

The extreme wind speed at top of the building was obtained by using Eq. (11). The value of $\alpha$ is taken here to be equal to 6.89 in Dhahran and 6.68 in Jeddah as validated in [12]. The extreme wind speed values at building heights of Dhahran tower (in Dhahran) and Golden Tower (in Jeddah) are examined respectively for different Return periods $(2,4,6,10,12,50,100 \& 200$ years $)$, and plotted in figure 7.

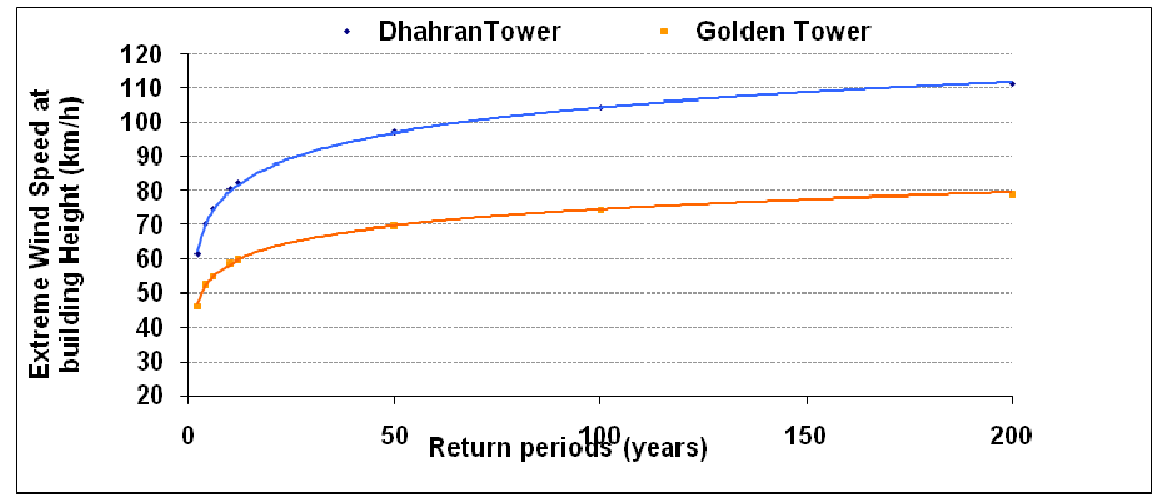

Figure 7: Reference Wind Speed at Building Height Versus the Return Period.

It is clear that wind profiles at the building heights recall those of the basic wind speed (figure 6). The extreme wind speed at the building height increases in a non-linear way, with the increasing of return period, at a lower rate for return periods exceeding 10 years. Dhahran Tower (200m height), situated in Dhahran, experiences a higher wind speed that reaches up to $110 \mathrm{~km} / \mathrm{h}$ at 200 years. On the other hand, the maximum wind speed reached by Golden tower which is higher $(205 \mathrm{~m})$, and that is situated in Jeddah, is $80 \mathrm{~km} / \mathrm{h}$. The lowest wind speeds are obtained for both considered buildings at 2 years return period (60 km/h for Dhahran Tower; and $47 \mathrm{~km} / \mathrm{h}$ for Golden Tower). The extreme wind speed sat the building height for 50-year and 100 years recurrence intervals present slight variation for both towers. The calculated values are respectively $97 \mathrm{~km} / \mathrm{h}$ at 50-year and $106 \mathrm{~km} / \mathrm{h}$ at 100-year return period for Dhahran Tower, and 70 $\mathrm{km} / \mathrm{h}$ at 50-year and $75 \mathrm{~km} / \mathrm{h}$ at 100 year for Golden Tower. Apparently, the extrapolation of extreme wind speeds at the building height of both towers is mainly controlled by the basic wind speed, which is higher in Dhahran, especially that the two buildings have approximate height and approximate power law exponents as well.

\subsection{Estimation of along-Wind Building Responses}

Engineers often consider the lifetime of a building ranging between 50 and 100 years for either design purpose or 
prediction of buildings responses. For this reason, the evaluation of along-wind responses for the two buildings discussed in this study, was firstly conducted for 100-year return period; which will maximize the value of the extreme wind speed at the building height; and consequently, the lateral induced responses.

\subsubsection{Along -Wind Building Responses in Function of the Damping Ratio}

The prediction of along wind building responses for Dhahran Tower and Golden Tower has been conducted by examining the effect of structural damping ratio ranging from 0.01 to 0.07 . Table 5 displays the calculated values of the velocity pressure (q), background response factor (Q), and peak factor for Resonance $g_{R}$ for each building, under extreme wind Data speed. Table 6 shows the values of the resonant factor, $R$ gust factor, $G_{f}$ the along-wind pressure (p), peak displacement, $x_{\max }$ and along wind acceleration $\ddot{x}_{\max }$ obtained for each damping ratio.

Table 5:Velocity Pressure and Peak Factor at 100-Year Return Period

\begin{tabular}{|c|c|c|}
\hline & Dhahran Tower (Dhahran) & Golden Tower (Jeddah) \\
\hline $\mathrm{VH}(\mathrm{km} / \mathrm{h})$ & 106 & 75 \\
\hline $\mathrm{q}(\mathrm{Pa})$ & 0.866 & 0.434 \\
\hline $\mathrm{Q}$ & 0.832 & 0.834 \\
\hline$g_{x}$ & 3.8 & 3.79 \\
\hline
\end{tabular}

Table 6: Along-Wind Building Responses for Different Values of Damping Ratios at 100-Year Return Period

\begin{tabular}{|c|c|c|c|c|c|c|c|c|c|c|} 
& \multicolumn{3}{|l}{ Dhahran Tower (Dhahran) } & \multicolumn{3}{l|}{ Golden Tower (Jeddah) } \\
\hline $\begin{array}{l}\text { Damping } \\
\text { Ratio }\end{array}$ & $\begin{array}{l}\text { Reson. } \\
\text { Factor }\end{array}$ & $\begin{array}{l}\text { Gust } \\
\text { Factor }\end{array}$ & $\begin{array}{l}\text { pressure } \\
(\mathbf{P a})\end{array}$ & $\begin{array}{l}\text { Displ. } \\
(\mathbf{m})\end{array}$ & $\begin{array}{l}\text { Accel. } \\
(\mathbf{m} / \mathbf{s} 2)\end{array}$ & $\begin{array}{l}\text { Reson. } \\
\text { factor }\end{array}$ & $\begin{array}{l}\text { Gust } \\
\text { factor }\end{array}$ & $\begin{array}{l}\text { Pressure } \\
(\mathbf{P a})\end{array}$ & $\begin{array}{l}\text { Displ. } \\
(\mathbf{m})\end{array}$ & $\begin{array}{l}\text { Accel. } \\
(\mathbf{m} / \mathbf{s} 2)\end{array}$ \\
\hline 0.01 & 2.24 & 2.25 & 1.842 & 0.0077 & 0.110 & 1.98 & 2.02 & 0.852 & 0.0048 & 0.061 \\
\hline 0.02 & 1.58 & 1.7 & 1.507 & 0.0058 & 0.075 & 1.4 & 1.54 & 0.708 & 0.0037 & 0.043 \\
\hline 0.03 & 1.29 & 1.46 & 1.3664 & 0.005 & 0.062 & 1.14 & 1.38 & 0.648 & 0.0032 & 0.035 \\
\hline 0.04 & 1.12 & 1.33 & 1.285 & 0.0045 & 0.053 & 0.99 & 1.23 & 0.613 & 0.0029 & 0.03 \\
\hline 0.05 & 1 & 1.24 & 1.232 & 0.0042 & 0.047 & 0.88 & 1.16 & 0.592 & 0.0028 & 0.027 \\
\hline 0.06 & 0.91 & 1.18 & 1.194 & 0.00406 & 0.043 & 0.81 & 1.11 & 0.575 & 0.0027 & 0.024 \\
\hline 0.07 & 0.84 & 1.13 & 1.166 & 0.0038 & 0.040 & 0.75 & 1.07 & 0.563 & 0.0025 & 0.023 \\
\hline
\end{tabular}

It can be noticed from Table 5 that Dhahran Tower and Golden Tower present a great matching between their background response factor and peak factor for Resonance, although the difference in their velocity pressure is significant. The pressure due to wind velocity experienced by Dhahran Tower is much higher $(0.866)$ with respect to the pressure obtained at Golden Tower (0.434). In effect, the building response factor and peak factor for resonance depend only on the geometrical configuration of the building.

The geometrical configuration examined in table 2, indicates that the two considered structures have approximate cross section (Dhahran Tower: $38.68 \mathrm{~m}$ x $29.58 \mathrm{~m}$ x $200 \mathrm{~m}$ and Golden Tower: $39 \mathrm{~m}$ x $26 \mathrm{~m}$ x $205 \mathrm{~m}$ ). That indeed explains the similarities in their response factor and peak factor, in spite of the difference in their slenderness ratio.

The variation of damping ratio has a great impact on the along wind structural response as shown in Table 6 . As the damping ratio increases, the along-wind induced pressure, peak displacement and acceleration decrease for both towers. At the same time, they present a great correlation with the Gust factor. For Dhahran Tower, the minimum value of the damping ratio of 0.01 results in the greatest gust factor of 2.25 and the highest wind -induced pressure of 1.842 . The largest peak displacement $(0.0077 \mathrm{~m})$ is two times greater than the value obtained for the highest damping ratio of 0.07 ; and the highest acceleration $\left(0.110 \mathrm{~m} / \mathrm{s}^{2}\right)$ is almost two times the smallest value, which is also calculated for 0.07 damping. 
Golden Tower experiences the largest along-wind induced responses among their values 2.02 for the Gust factor, 0.852 for the wind -induced pressure, $0.0048 \mathrm{~m}$ for the peak displacement and $0.061 \mathrm{~m} / \mathrm{s}^{2}$ for the along-wind acceleration. The increase of the inherent structural damping ratio of each considered tower, leads to gradual reduction in the resonant factor $\mathrm{R}$, which reduces gradually the gust factor, and consequently the towers vibrate less. The maximum value of dampingof 0.07 provides a resonant factor of $0.84(0.75)$, Gust factor of $1.13(1.07)$, along-wind induced pressure of $1.16(0.563)$ for Dhahran Tower and Golden Tower respectively. The results also reveal peak displacement of $0.0038 \mathrm{~m}$; and along-wind peak acceleration of 0.04 for Golden Tower. It is clear that the along-wind induced response of Golden Tower is always less in terms of pressure, displacement and acceleration.

In order to investigate the building's occupant comfort to the obtained buildings responses, the along-wind pressure and acceleration are plotted with respect to the damping ratios. It can be inferred from Figure 8 that the windinduced pressure profile is decreasing non-linearly with the increase in damping ratio. For Dhahran Tower, the rate of decrease in pressure is $0.3 \mathrm{~Pa}$, when the damping ratio increases from 0.01 to 0.02 ; however, it becomes $0.1 \mathrm{~Pa}$ when the damping ratio gets higher for Dhahran Tower. The pressure profile associated with Golden Tower indicates the same trend; but the rate of variation is less $(0.2 \mathrm{~Pa})$ at the smaller damping.

Figure 9 reveals that the along-wind induced acceleration experienced by Dhahran Tower exceeds $0.1 \mathrm{~m} / \mathrm{s}^{2}$ at the smallest damping ratio; which refers to level 3 classified among Human sensitivity levels against acceleration (Table 1). Occupants are more likely to feel the building vibration, and the deskwork might be affected. The induced building motion can still be slightly perceived for damping values up to 0.04 where the acceleration is $0.05 \mathrm{~m} / \mathrm{s}^{2}($ level 2 ), and then for larger damping ratios, occupants will not be able to perceive any motion (level 1). On the other hand, Jeddah Tower shows lower peak accelerations due to the lower induced-pressure. It is classified under Level $2\left(0.05-0.1 \mathrm{~m} / \mathrm{s}^{2}\right)$ for the two damping ratios $(0.01$ and 0.02$)$ where only sensitive people can perceive motion. For higher values of damping, the acceleration is less than $0.05 \mathrm{~m} / \mathrm{s}^{2}$ (level 1) and the building vibration is imperceptible.

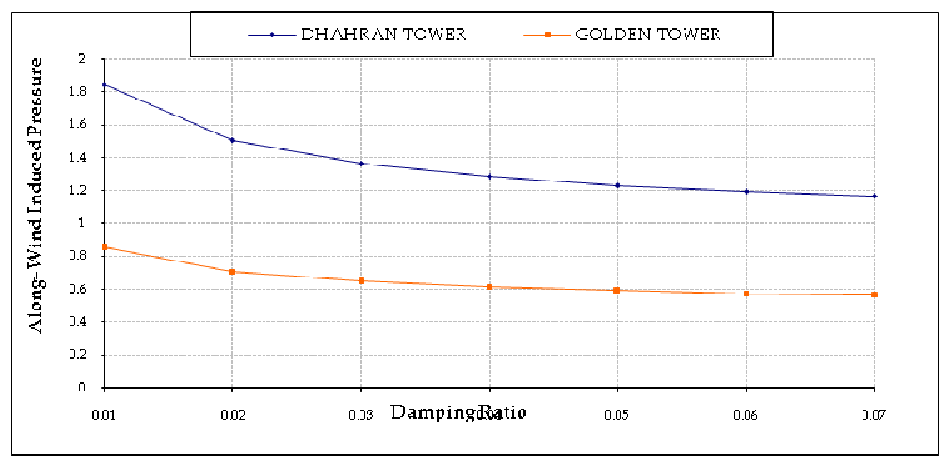

Figure 8: Along-Wind Pressure for Different Structural Damping at 100-Year Return Period. 


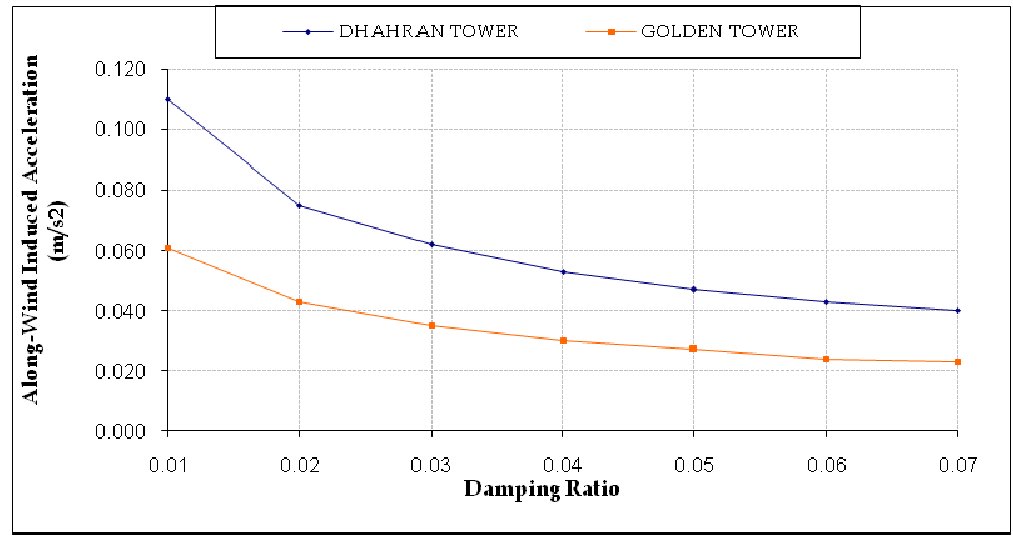

Figure 9: Along-Wind Acceleration for Different Structural Damping at 100-Year Return Period.

\subsubsection{Along -Wind Building Responses in Function of the Basic Wind Speed}

The along-wind induced responses were explored in accordance with the wind speed at the building height $(\mathrm{VH}=106 \mathrm{~km} / \mathrm{h}$ for Dhahran Tower, and $\mathrm{VH}=75 \mathrm{~km} / \mathrm{h}$ for Jeddah Tower) for 100 years return period. The reason that stands behind this examining is that the two considered structures are characterized with approximate geometric configuration; and they are located in similar terrain roughness.

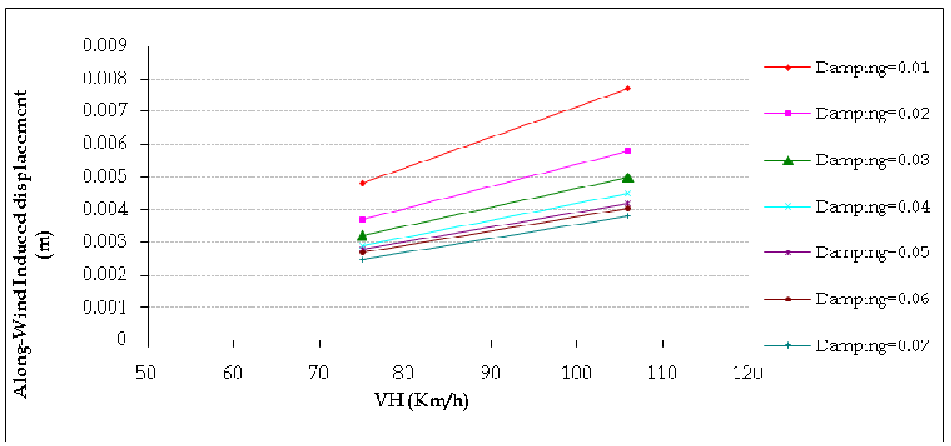

Figure 10: Along-Wind Displacements Versus Reference Wind Speed at Building Height for all Structural Damping Ratios.

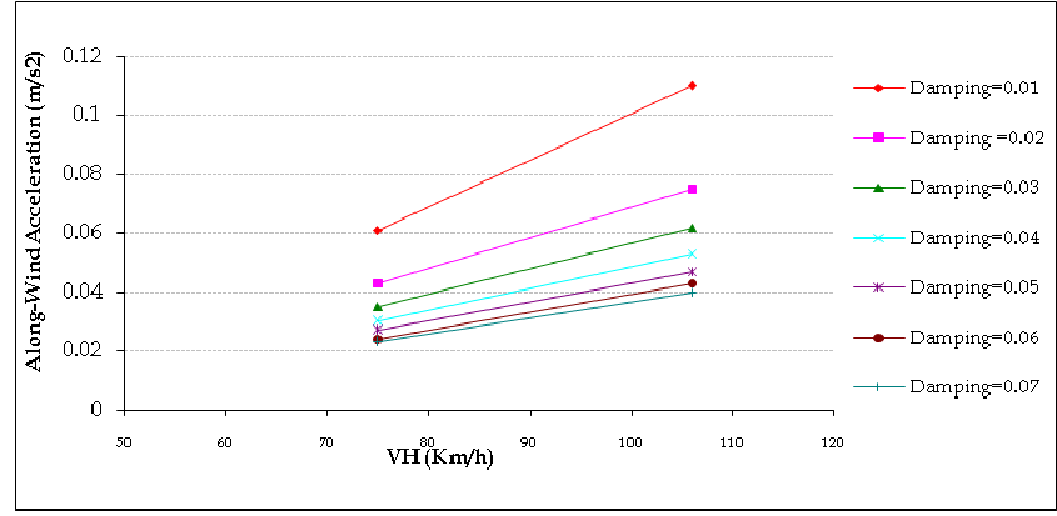

Figure 11: Along-Wind Acceleration Versus Reference Wind Speed at Building Height for all Structural Damping Ratios.

Figures 10 and 11 show that, the along-wind induced displacement and acceleration increase significantly when the wind speed at the building height increases from $75 \mathrm{~km} / \mathrm{h}$ to $106 \mathrm{~km} / \mathrm{h}$. This trend verifies the values shown in table 5 , 
where the velocity pressure $q$ is seen to vary accordingly. It is then expected to find that the velocity pressure and all three building responses increase with increasing the reference wind speed, since they are all proportional to the reference wind speed. On the other hand, the damping ratio seems to reduce the peak displacement and acceleration at lower rates for damping above $3 \%$. This result is rational since more damping is expected to make a structure stiffer, a trend reflected as well by the spring-mass-damper analogy. It is worth noting that reference wind speed exceeding $100 \mathrm{~km} / \mathrm{h}$ induces alongwind building accelerations above $0.1 \mathrm{~m} / \mathrm{s}^{2}$, which implies the Level 3 motion perception among human sensitivity levels against acceleration.

\subsubsection{Along -Wind Building Responses in Function of the Return Period}

The Along-wind building responses in terms of pressure, displacement and acceleration have been examined, in detail in this part, for Dhahran Tower and Golden Tower, for return periods up to $100(2,4,6,10,12,50 \& 100$ years), and with respect to the smaller (0.01), medium (0.04) and the maximum (0.07) damping ratios. Figures 12,13 and 14 represent the results graphically where the plain lines and dashed lines refer to Dhahran Tower (in Dhahran) and Golden Tower (in Jeddah) respectively.

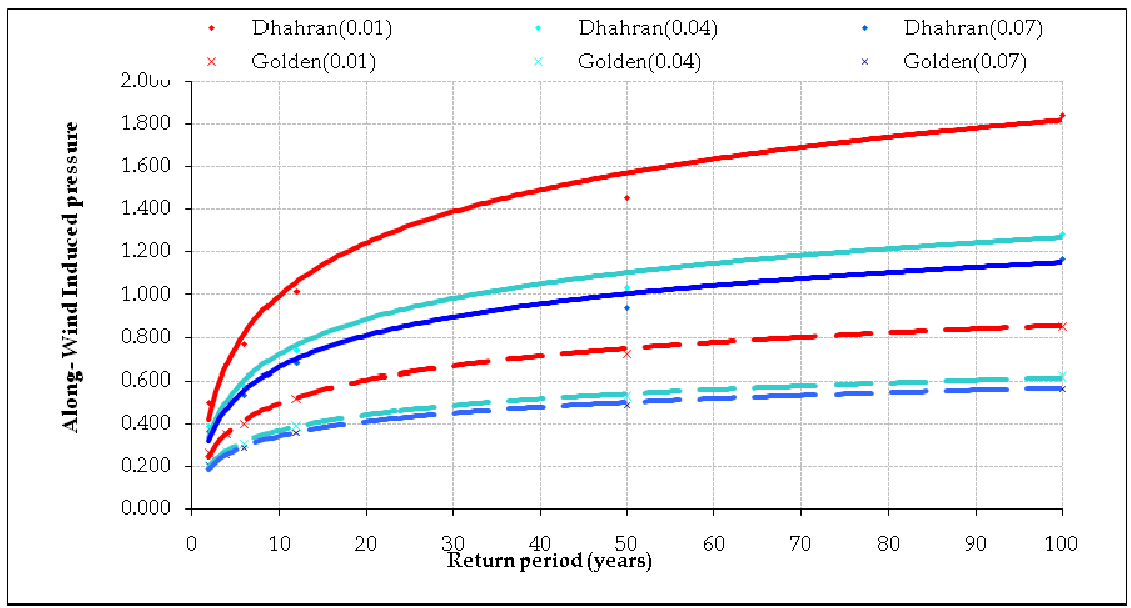

Figure 12: Along Wind Induced Pessure Versus the Return Period.

Figure 12 illustrates the along-wind induced pressures for Dhahran Tower and Golden Tower under the variation of two factors: return period and damping ratio. It can be seen that pressure loads increase for both towers when the return period increases, but at various rates. Moreover, increasing the structural damping ratios results in a drop in the wind induced pressures. The pressure curve demonstrates non-linear profile; which can be associated with a logarithmic trend by using a fitting data technique. Dhahran Tower has the highest magnitudes of pressure for all return periods. For return periods less than 10 years, the induced pressures increase gradually at a rate of $0.1 \mathrm{~Pa}$ for each 2 years varying from $0.3 \mathrm{~Pa}$ up to $0.8 \mathrm{~Pa}$. The increase of the damping ratio from 0.04 to 0.07 produces a slight reduction in pressure loads of $0.1 \mathrm{~Pa}$. When the return period changes from 12 to 50 years, the rate of variation in pressure becomes $0.45 \mathrm{~Pa}$, and it is not much affected by the variation of damping value. On the other hand, the along wind induced pressures observed at Golden Tower look smaller with a smaller rate of variation, that is why the corresponding curves are less steep, pressures are less than 0.5 $\mathrm{Pa}$ when the recurrence interval is less than 12 years.

The curves corresponding to damping ratios (0.04) and (0.07) almost collapse for return periods smaller than 10 years; while the impact of the variation from the mild value to maximum damping seems to be small. It can be said that 
pressure profiles are divided into two regions: the low-return period plateau (less than 10 years) and the non -linear region for return periods ranging between 10 and 100 years.

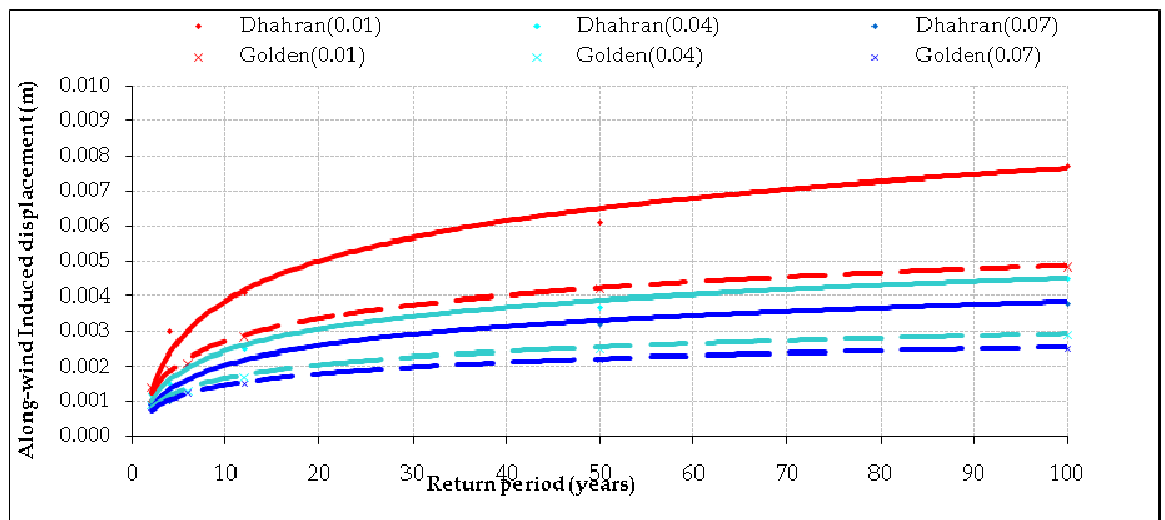

Figure 13: Along Wind Induced Displacement Versus the Return Period.

The Along -wind induced displacements for the two towers are seen in figure 13. The increase in peak displacements with the return period can be also fitted to logarithmic profile; and the smaller damping values result in greatest displacements. For return periods less than 12 years, the along-wind sway might go up to $0.004 \mathrm{~m}$. When return periods are larger, it increases at a higher rate of variation for the lower damping. In terms of comparison between the two towers, it can be noticed that the peak displacement of $0.008 \mathrm{~m}$ observed at Dhahran Tower for 100 years, exceeds that of Golden Tower by $50 \%$ at the lowest damping ratio of 0.01 . Also, there is a clear matching between the displacement of Golden Tower with 0.01 damping and Dhahran Tower when using a damping of 0.04. In addition, the graph indicates that the effect of varying the damping ratio from 0.04 to 0.07 for Golden Tower is more pronounced at return periods higher than 12 years.

Figure 14 reveals the peak acceleration for both towers with respect to the return period as well as the damping ratio. As the return period increases, the along-wind induced acceleration increases in a non-linear way. Also, the damping ratios contribute to the reduction in magnitudes of acceleration. Dhahran Tower is characterized with the highest peak acceleration, and the curves corresponding to both towers almost converge at the smallest return period ( $\mathrm{T}=2$ years); where the peak acceleration at the building height is less than $0.02 \mathrm{~m} / \mathrm{s}^{2}$.

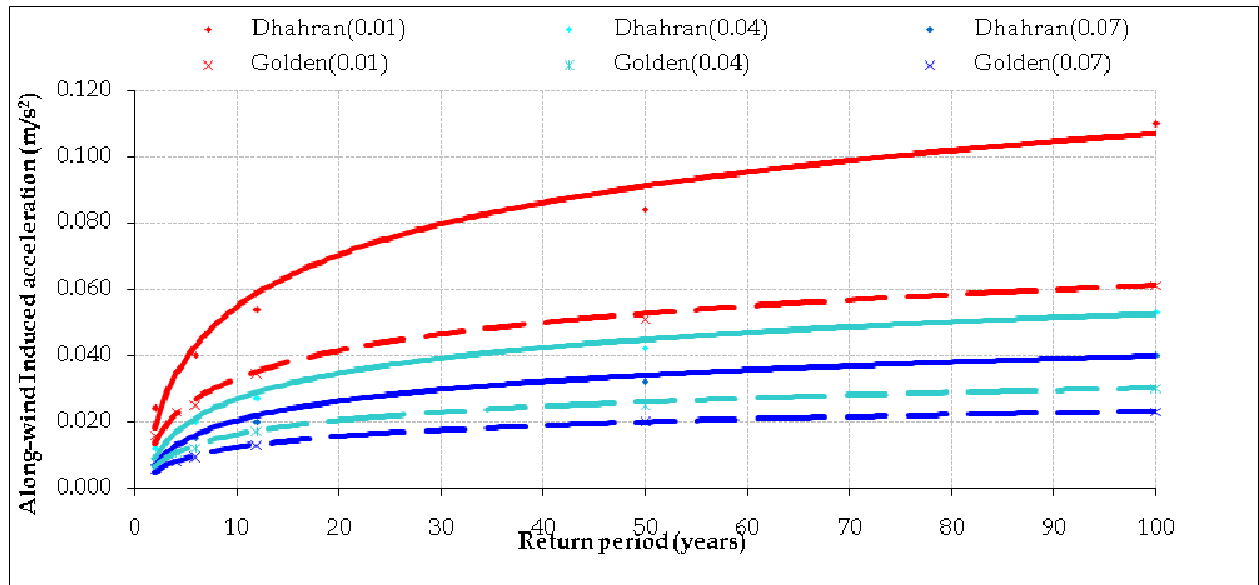

Figure 14: Along Wind Induced Acceleration Versus the Return Period.

In terms of the Human sensitivity classification levels as per table [1], it can be said that Dhahran Tower accompanied with the smallest damping ratio of 0.01 , falls in level 1 (accel. $\left.<0.05 \mathrm{~m} / \mathrm{s}^{2}\right)$ for return periods less than 10 
years, level $2\left(\right.$ accel. $\left.=0.05-0.1 \mathrm{~m} / \mathrm{s}^{2}\right)$ for return periods ranging between 10 and 100, and it falls under Level 3 (accel. $=$ $0.1-0.25 \mathrm{~m} / \mathrm{s}^{2}$ ) for return period equal to 100 years. When the damping ratio increases to 0.04 and 0.07 , the tower then falls under level 1 for all return periods. While for Golden tower, it is classified within level 1 for return periods less than 50 years, and within level 2 for return periods exceeding 50 years; at the damping ratio of 0.01.In addition, when the structural damping is considered as 0.04 and 0.07 , the peak acceleration values are reduced significantly until 0.03 and 0.02 $\mathrm{m} / \mathrm{s}^{2}$; then Golden Tower will be classified within Level 1.

\section{CONCLUSIONS}

The prediction of along-wind induced responses for two towers located in Saudi Arabia has been conducted in the present study with respect to the variation of two parameters: the structural damping ratio and the return period. The calculations were carried out for Dhahran Tower in Dhahran city and Golden Tower in Jeddah, based on hourly wind speed data collected over the past 11 years (2009 to 2019). The annual extreme wind speed data distribution was modeled by using Gumbel linear regression, which led to the maximum theoretical return period of 12 years. The wind speed analysis revealed that Dhahran tower is prone to higher wind speeds which exceed $100 \mathrm{~km} / \mathrm{h}$ at the building height; starting from 100 years return period. The wind speed at the top of Golden Tower is $25 \%$ less for return periods smaller than 12 years, and by $30 \%$ for higher recurrence intervals. It has been found that the increase in the damping ratio from 0.01 to 0.07 cause a reduction of the along-wind responses of both towers but at different rates, with respect to the considered return period. The gradual increase in the return period alone from 2 to 100 years contributes to a non-linear increase of wind-induced pressures, displacements and accelerations for both buildings. Golden Tower vibrates the most for return periods exceeding 50 years at the lowest damping atio; while it offers reduced displacements and accelerations for damping above 0.04 for return periods ranging from 2 to 100 years. On the other hand, the level of discomfort, seems to be much higher for occupants in Dhahran Tower, due to the pronounced along-wind induced lateral responses. At the smallest damping ratio of 0.01, DhahranTower experiences the largest peak displacements and two times induced pressure; which implies its classification under level 3 of Human Sensitivity Levels for return periods equal or higher than 100 years. The vibrations are minimized when the return period decreases reaching Level 1 for return period less than 10 years. When the damping ratio increases to 0.04, Dhahran Tower falls under Level 1 for all return periods.

\section{REFERENCES}

1. Vikram, M.B.,Chandradhara, G. and B. Keerthi Gowda, A study on effect of wind on the static and dynamic analysis. International Journal of Energing trends in Engineering and Development, 2014. 4 (3).

2. Aly, A.M., Influence of turbulence, orientation, and site configuration on the response of buildings to extreme wind. The Scientific World Journal, 2014. 2014.

3. Hasan, RaadAbed Al-Jallal. "Behaviour of beam and wall outrigger in high-rise building and their comparison." International Journal of Civil, Structural, Environmental and Infrastructure Engineering Research and Development 6.1 (2016): 19-30.

4. Mendis, P., et al., Wind loading on tall buildings. Electronic Journal of Structural Engineering, 2007.

5. Lawrence, G., Serviceability limit states under wind load. Engineering journal of american institute of steel construction, 2003.

6. Longarini, N., et al., Structural improvements for tall buildings under wind loads: comparative study. Shock and Vibration, 2017. 2017. 
7. Joshi, Krishna. "Application of Energy Concepts for Green Buildings." International Journal of Civil, Structural, Environmental and Infrastructure Engineering Research and Development (IJCSEIERD) ISSN (P) (2016): 2249-6866.

8. Tozan, S., K. Güler, and B. Erkuş, Wind Comfort Assessment of a Tall Building According to Various Structural Codes, 2013.

9. Li, Q., et al., The effect of amplitude-dependent damping on wind-induced vibrations of a super tall building. Journal of Wind Engineering and Industrial Aerodynamics, 2003. 91(9): p. 1175-1198.

10. Al Balushi, J. and A. John, Effect of Wind and Structural Parameters on Wind-Induced Acceleration of RC Building. 2014.

11. Nezami, Mohsen, and MozhganRahi. "Fragility Analysis of Existing Steel Building and Possible Rehabilitation by Fuzzy Expert Systems Under Blast and Dynamic Loads." International Journal of Civil, Structural, Environmental and Infrastructure Engineering Research and Development (IJCSEIERD) ISSN (P) (2016): 2249-6866.

12. SBC, Wind Load Criteria and Design Wind Load procedures. 2007, Saudi Building Code National Committee.

13. Dym, C.L. and H.E. Williams, Estimating fundamental frequencies of tall buildings. Journal of Structural Engineering, 2007. 133(10): p. 1479-1483.

14. Timeand Date, Time and Date. n.d.

15. Arafah, A. and G. Siddiqi, Estimation of the Design Wind Speeds for the Kingdom of Saudi Arabia Based on Short-term Records. Journal of King Saud University-Engineering Sciences, 1995. 7(1): p. 47-65.

16. Patel, H. S., and H. S. Patel. "Effect On Compressive And Flexural Strength Of High-Performance Concrete Incorporating Alccofine and Fly Ash." International Journal of Civil, Structural, Environmental and Infrastructure Engineering and Development 3.2 (2013): 109-114.

17. Vivekanandan, N., Comparison of Estimators of Extreme Value Distributions for Wind Data Analysis. Bonfring International Journal of Data Mining, 2012. 2(3): p. 16-20.

18. Arafah, A., G. Siddiqi, and A. Dakheelallah, Extreme wind speeds in the Kingdom of Saudi Arabia. Arabian Journal For Science and Engineering, 1992. 17: p. 337-337.

19. El-Shanshoury, G.I. and A. Ramadan, Estimation of extreme value analysis of wind speed in the north-western coast of Egypt. Arab Journal of Nuclear Science and Applications, 2012. 45(4): p. 265-274.

20. Engineers, A.S.o.C., Minimum Design Loads for Buildings and Other Structures, ANSI/SEI7 $\square$ 10. 2010.

21. Zhou, Y., A. Kareem, and M. Gu, Mode shape corrections for wind load effects. Journal of engineering mechanics, 2002. 128(1): p. 15-23. 